\title{
PLATÃO E A APRENDIZAGEM DO OLHAR EM JOÃO GUIMARÃES ROSA
}

\author{
PLATO AND THE LEARNING OF THE LOOK IN JOÃO GUIMARÃES ROSA
}

João Batista Costa Filho*

\section{RESUMO}

Guimarães Rosa foi o escritor que, como poucos, soube explorar as potencialidades do olhar na experiência de seus personagens para que estes criassem, a partir daí, um universo simbólico para a renovação de si mesmos e do mundo que os cerca. $\mathrm{O}$ aprendizado do olhar em Rosa pode ser comparado com o processo em que o prisioneiro, na alegoria da caverna, liberta-se, e sucessivamente passa de um estado de ignorância, em que via apenas o ilusório e o aparente, para a visão das formas puras e inteligíveis. Platão compara o sol com a forma do Bem. Um texto do escritor mineiro ilustra esse aprendizado do olhar em paralelo com a visão platônica: a novela Campo geral. Nela, o personagem central é uma criança míope de oito anos que, num processo de descoberta do mundo, renova o seu olhar a cada momento, a exemplo do prisioneiro liberto da alegoria da caverna.

PALAVRAS-CHAVE: Guimarães Rosa. Platão. Olhar. Campo geral.

\section{ABSTRACT}

Guimarães Rosa was the author who, as few, knew how to exploit the look potentialities in his character's experiences to enable them to create, from then on, the symbolic universe for the renewal of themselves and the world around. The learning of the look in Guimarães Rosa can be compared with the process where the prisioner, in the allegory in the cave, releases himself, and successively goes from an ignorance state, when he could only saw the illusory and apparent, to the intelligible and pure forms. Plato compares the sun with the Good forms. A specific text of the mineiro writer illustrates this learning of the look in parallel with the platonic vision: the Campo geral novel. Its main character is an eight-years-old shortsighted child who, in his world discovery proccess, renews his outlooks at each moment, at is done by prisioner released from the allegory of the cave.

KEY-WORDS: Guimarães Rosa. Plato. Look. Campo geral.

Queria uma coragem de abrir a janela, espiar no mais alto, agarrado com os olhos, elas todas, as sete estrelas.

Eu espio a lua, Dito, que fico querendo pensar muitas coisas de uma vez, as coisas todas...

(ROSA, 2001)

\footnotetext{
* Mestrando em Estudos de Linguagens da Universidade Federal do Mato Grosso do Sul. E-mail: jbcostaf@hotmail.com.
} 
O tema do olhar é recorrente em Guimarães Rosa. Em sua obra-prima, Grande sertão: veredas, o personagem principal Riobaldo, toda vez que quer chamar a atenção de seu interlocutor, usa a expressão "mire veja”. Sua clara intenção é fazer despertar em seu ouvinte, um homem instruído, doutor da cidade, o seu olhar para outras realidades que até então estavam ocultas. Fazer com que ele enxergue além das aparências, que veja o invisível no visível, segundo uma expressão utilizada por Merleau-Ponty (2000), ultrapassando, assim, a lógica em que está acomodado. O “doutor”, acostumado a uma visão estereotipada, conforme os padrões em que foi educado, é despertado por Riobaldo para que o seu olhar seja dirigido par o suprassenso, o misterioso, o transcendente e transracional.

Ainda no Grande sertão: veredas, o olhar de Riobaldo se encanta à primeira vista quando se encontra pela primeira vez com Diadorim, na figura daquele menino de "esmerados esmartes olhos, botados grande, folhudas pestanas, luziam um efeito de calma" (ROSA, 2006, p. 103). Foram os olhos de Diadorim que o atraíram e o conduziram às aventuras junto aos jagunços no sertão mineiro.

Além de seu romance, também em seus contos e novelas Guimarães Rosa procurou, por meio de seus personagens, transmitir o encanto que há por trás da realidade aparente. Exemplos ao longo de sua obra estão presentes em Sagarana (São Marcos), Primeiras estórias ("As margens da alegria", "O espelho" e "Os cimos") e em Tutameia, terceiras estórias. O texto, no entanto, que melhor retrata essa questão do olhar na obra rosiana é “Campo geral”, novela que faz parte do livro Manuelzão e Miguilim (Corpo de baile). Nele sobressai o olhar sensível e inquiridor de uma criança de oito anos, que busca compreender o mundo em que vive. Nesse sentido, Campo geral é uma obra transcendental, pois provoca a visão do invisível e a luta contra o automatismo e a lógica da sobrevivência adulta. O leitor participa junto com o narrador e a personagem desse desvelamento da realidade provocado pela visão poética da imaginação criadora infantil. Miguilim, assim como tantos outros personagens rosianos, apresenta um olhar perquiridor, especulativo e contemplativo da realidade, capaz de ampliar nossa concepção de mundo muito além do aparente, de uma suposta normalidade.

Há um platonismo no modo de ver as coisas por parte de Guimarães Rosa. Traçar um alinhamento entre um autor de ficção brasileiro do século XX e um pensador de quase dois milênios e meio atrás parece arbitrário. No entanto, em uma determinada carta endereçada ao seu tradutor italiano, ele admite a dívida intelectual em relação a Platão e ao neoplatonismo (BIZZARRI, 1980). As epígrafes contendo citações de Plotino em Corpo de baile por si sós 
confirmam a presença dessas leituras filosóficas na obra rosiana. Nos prefácios de Tutameia, Guimarães Rosa lança pistas que evidenciam o pensamento platônico em sua obra, como no seguinte trecho de "Aletria e hermenêutica": “A vida também é para ser lida. Não literalmente, mas em seu suprassenso. E a gente, por enquanto, só a lê por tortas linhas. Estáse a achar que ri. Veja-se Platão, que nos dá o Mito da Caverna” (ROSA, 1967, p. 4). Em outro prefácio, "Sobre a escova e a dúvida", o autor mineiro afirma que seu "duvidar é da realidade sensível aparente - talvez só um escamoteio das percepções" (ROSA, 1967, p. 148).

José Américo Motta Pessanha (1995, p. 79), no ensaio Platão: as várias faces do amor, assim descreve o filósofo grego: bom prosador e poeta, imaginativo, que utiliza variados recursos de linguagem, diálogos, demonstrações, mitos, alegorias; pensamento alusivo, analógico, que se move nos domínios do razoável e do plausível; imagens e metáforas a serviço da tarefa de iluminação; e construção multifacetada, assistemática, plural, constituída por sucessivas tentativas, sucessivos ensaios. Percebe-se, por meio das características descritas em relação a Platão, que muitas delas são coerentes com que se pensa a respeito de Guimarães Rosa.

Platão, ainda que tenha banido os poetas de sua polis ideal, ele próprio era um artista da palavra que se utilizava dos meios expressivos da linguagem para tornar mais acessíveis os conceitos de que dispunha. Como a linguagem corrente não é capaz de expressar aquilo que se pretende comunicar, Platão faz uso de analogias, metáforas, mitos e alegorias para que todos alcancem, por força da imagem, a visão dos conceitos. Para se ter uma aproximação do que é a forma do Bem, Platão empregou a analogia do sol. Para explicar a estrutura e a divisão da realidade, apresentou a alegoria da reta segmentada, com o caminho ascensional que vai do mundo sensível para o mundo inteligível, da doxa para a episteme. Na célebre Alegoria da caverna, Platão descreve metaforicamente o processo sucessivo de aprendizagem que se inicia na visão de sombras, ilusões e imitações do mundo sensível para a visão direta da realidade plena e pura do mundo inteligível. Trata-se, portanto, de um itinerário que vai da sombra à luz.

Esse caminho árduo realizado pelo prisioneiro, num esforço de escapar da caverna, por consequência de um mundo ilusório e de sombras, para, enfim, ver a realidade como ela é, pode ser, de certa forma, comparado com o percurso traçado pelo personagem Miguilim de Campo geral. O ambiente sombrio do Mutúm, localidade onde reside Miguilim e se desenvolve o enredo da novela, representa, de certa forma, uma caverna, à semelhança do que ocorre na alegoria platônica: 
Um certo Miguilim morava com sua mãe, seu pai e seus irmãos, longe, longe daqui, muito depois da Vereda-Frango-d'Água e de outras veredas sem nome ou pouco conhecidas, em ponto remoto, no Mutúm. [...]. É um lugar bonito, entre morro e morro, com muita pedreira e muito mato, distante de qualquer parte; e lá chove sempre...[...]. Queixava-se, principalmente nos demorados meses chuvosos, quando carregava o tempo, tudo tão sozinho, tão escuro, o ar ali era mais escuro. [...]. Entretanto, a mata, ali perto, quase preta, verde-escura, punha-lhe medo (ROSA, 2001, p. 27-29) ${ }^{1}$

As condições sombrias da localidade são reforçadas nesta passagem:

Lá era sem luz, mesmo de dia quase que só as labaredas mal alumiavam. Miguilim era mais pequeno, tinha medo de tudo, [...] daí viu, os olhos dele vendo: viu nada, só conheceu que o escuro estava sendo mais maldoso, em redor - e o treslinguar do fogo - era uma mata-escura, mata em que o verde vira preto, e o fogo pelejava para não deixar aquilo tomar conta do mundo, estremeciam mole todos os sombreados. (p. 61).

Miguilim é extremamente sensível. Dos “prisioneiros da caverna do Mutúm” ele, sem dúvidas, é o que reúne as melhores condições para escapar dessa realidade sombria e ilusória e empreender o caminho do autoconhecimento e da visão privilegiada da realidade efetiva. A sensibilidade aguçada do personagem pode ser ilustrada nas passagens a seguir:

[...] cheirava à claridade. Depois, na alegria num jardim, deixavam-no engatinhar no chão, meio àquele fresco das folhas, mas o mais lindo era o das frutinhas vermelhas escondidas por entre folhas - [...] cheiro de alegriazinha (p. 31).

[...] via as formiguinhas entrando e saindo e trançando, os caramujinhos rodeando as folhas, no sol e na sombra, por onde rojavam sobrava aquele rastrío branco, que brilhava" (p. 37).

O gaturamo, tão podido miúdo, azulzinho no sol, tirintintim, com brilhamentos, mel de melhor - maquinazinha de ser de bem cantar... (p. 45).

Que é isso, menino, que você está escondendo? - É a joaninha, Pai - Que joaninha? Era o besourinho bonito, pingadinho de vermelho (p. 127).

Naturalmente questionador e ansioso por saber o fundamento e o porquê de todas as coisas, Miguilim desenvolve diálogos com as pessoas de sua relação como se fora um "pequeno Sócrates" a extrair conceitos para a compreensão da realidade. Há nos questionamentos de Miguilim preocupações em relação à justiça, ao princípio e finalidade das coisas, ao certo e errado, à existência do bem e do mal e, também, quanto à beleza:

\footnotetext{
${ }^{1}$ Nas próximas citações de Campo geral serão registradas apenas as páginas, pois todas fazem parte do livro Manuelzão e Miguilim (ROSA, 2001).
} 
O gaturaminho das frutas, ele merece castigo, Dito? (p. 45).

Tio Terez, o senhor acha que o Mutúm é lugar bonito ou feioso? (p. 30)

Dito, mesmo você acha, eu sou bobo de verdade? - É não, Miguilim, de jeito nenhum. Isso mesmo que não é. Você tem juízo por outros lados... (p. 86).

Dito, como é que a gente sabe certo como não deve de fazer alguma coisa, mesmo os outros não estando vendo? - A gente sabe, pronto. (p. 86).

Mãe, o que a gente faz, se é mal, se é bem, ver quando é que a gente sabe? (p. 87).

Vaqueiro Jé: malfeito como é, que a gente se sabe? (p. 87).

Mãe, que é que é o mar, Mãe? [...] Pois, Mãe, então mar é o que a gente tem saudade? (p. 91).

Mãe, mas por que é, então, para que é, que acontece tudo? (p. 91)

Há um fato crucial na narrativa que, no entanto, só é revelado no final da novela: Miguilim é míope. Um médico em visita ao Mutúm constata a deficiência visual da criança. Empresta-lhe os óculos e Miguilim, então, passa a enxergar com clareza os rostos de seus familiares e a beleza da natureza circundante. O doutor convida Miguilim para acompanhá-lo e ir morar com ele na cidade. Na despedida, Miguilim pede os óculos novamente ao médico. Numa cena comovente e magistralmente narrada, temos a ocasião em que o prisioneiro sai em definitivo da caverna e passa a ter uma visão mais ampla e luminosa:

\footnotetext{
Miguilim olhou. Nem não podia acreditar! Tudo era uma claridade, tudo novo e lindo e diferente, as coisas, as árvores, as caras das pessoas. Via os grãozinhos de areia, a pele da terra, as pedrinhas menores, as formiguinhas passeando no chão de uma distância (p. 149).

E Miguilim olhou para todos, com tanta força. Saiu lá fora. Olhou os matos escuros de cima do morro, aqui a casa, a cerca de feijão bravo e são-caetano; o céu, o curral, o quintal; os olhos redondos e os vidros altos da manhã. Olhou, mais longe, o gado pastando perto do brejo, florido de são-josés, como um algodão. $\mathrm{O}$ verde dos buritis, na primeira vereda. O Mutúm era bonito! Agora ele sabia. (p. 152).
}

Miguilim sai da caverna, daquela realidade obscura e ilusória para, enfim, enxergar a forma plena da realidade, representada simbolicamente pela colocação dos óculos. Trata-se de um momento epifânico, semelhante àquele em que o prisioneiro da alegoria platônica escapa dos grilhões em que vivia, para ter acesso, por meio de seus próprios olhos, ao mundo real até então desconhecido. Ao realizar o percurso da sombra à luz, Miguilim passou por um processo árduo de aprendizagem em que o olhar foi se construindo por etapas. Assim como muitos dos personagens rosianos, soube revelar o que há de verdadeiramente real que se 
esconde por trás da fachada ilusória e aparente da realidade. A leitura de Guimarães Rosa permite essa abertura para o exercício do olhar, para essa instigante aventura de enxergar o invisível no visível, o mistério e a poesia que há por trás de todas as coisas.

\section{REFERÊNCIAS}

ABBAGNANO, Nicola. Dicionário de filosofia. São Paulo: Martins Fontes, 1999.

BENSON, Hugh H. Platão. Rio de Janeiro: Editora Forense Universitária, 1993.

BIZZARRI, Edouardo. João Guimarães Rosa: correspondência com seu tradutor italiano Edouardo Bizarri. 2. ed. São Paulo: Instituto Cultural Ítalo-Brasileiro, 1980.

LEBRUN, Gerard. Sombra e luz em Platão. In: NOVAES, Adauto (org.). O olhar. São Paulo: Companhia das Letras 1995.

MANTOVANI, Juliana Estanislau de Ataíde. Vi. Ver é muito perigoso. Leitura do olhar em Grande sertão: veredas. Dissertação de mestrado (Literatura e Práticas Sociais), UNB, 2013.

MERLEAU-PONTY, Maurice. O visível e o invisível. 3. ed. São Paulo: Perspectiva, 2000.

MODRAK, Deborah K. W. Platão: uma teoria da percepção ou um aceno à sensação? In: BENSON, Hugh H. Platão. Rio de Janeiro: Editora Forense Universitária, 1993.

NOVAES, Adauto (org.). O olhar. São Paulo: Companhia das Letras, 1995.

NOVAES, Adauto. De olhos vendados In: NOVAES, Adauto (org.). O olhar. São Paulo: Companhia das Letras 1995, p. 9.

PESSANHA, José Américo Mota. Platão: as várias faces do amor. In: NOVAES, Adauto. O sentido da paixão. Companhia das Letras, 1995.

PLATÃO. A república. São Paulo: Nova Cultural, 1997.

ROSA, João Guimarães. Tutameia: terceiras estórias. Rio de Janeiro: José Olympio, 1967.

ROSA, João Guimarães. No Urubuquaquá, no Pinhém (Corpo de baile). Rio de Janeiro: José Olympio, 1976.

ROSA, João Guimarães. Noites do sertão (Corpo de baile). 8. ed. Rio de Janeiro: Nova Fronteira, 1998.

ROSA, João Guimarães. Manuelzão e Miguilim (Corpo de baile) 11. ed. Rio de Janeiro: Nova Fronteira, 2001.

ROSA, João Guimarães. Grande sertão: veredas. Rio de Janeiro: Nova Fronteira, 2006. 
ROSA, João Guimarães. Primeiras estórias. Rio de Janeiro: Nova Fronteira, 2015. Formato digital Kindle.

ROSA, João Guimarães. Sagarana. Edição. especial, Rio de Janeiro: Nova Fronteira, 2015. Formato digital Kindle.

SANTOS, Iolanda Cristina Santos. O aprendizado do olhar em João Guimarães Rosa. Tese (Doutorado), Ciência da Literatura, UFRJ, 2006. 